\title{
Relationship Between Medication Adherence and Health Beliefs Among Patients with Hypertension in Oman Pilot study
}

"Huda Al-Noumani, ${ }^{1}$ Jia-Rong Wu, ${ }^{2}$ Debra Barksdale, ${ }^{3}$ Esra Alkhasawneh, ${ }^{4}$ George Knafl, ${ }^{2}$ Gwen Sherwood ${ }^{2}$

$$
\begin{aligned}
& \text { العلاقة بين الالتزام بالأدوية والمعتقدات بين المرضى الذين يعانون } \\
& \text { من ارتفاع ضغط الدم في عمان } \\
& \text { دراسة ارتيادية }
\end{aligned}
$$

هدى النعمانية، جيا رونغ وو، ديبرا باركسديل، إسراء الخصاونة، جورج كنافل، جوين شيروود

\begin{abstract}
ABST RACT: Objectives: The prevalence of hypertension (HTN) in Oman is alarmingly high and patient adherence to antihypertensive medications is inadequate. This study aimed to assess the relationship between medication adherence and health beliefs among Omani patients with HTN. Methods: This descriptive cross-sectional pilot study was conducted in December 2015 and included 45 patients with HTN recruited from four primary health centres in Al Dakhiliyah and Muscat governorates, Oman. Medication adherence and health beliefs were assessed using the Morisky Medication Adherence Scale (MMAS), Beliefs about Medicines Questionnaire, Brief Illness Perception Questionnaire and the revised Medication Adherence Self-Efficacy Scale. Results: The mean MMAS score was $5.3 \pm 2.0$, with $48.9 \%$ of patients reporting high adherence. Higher self-efficacy and stronger beliefs regarding medication necessity were significantly related to adherence $(P=0.012$ and 0.028 , respectively). Conclusion: The findings of this pilot study emphasise the role of health beliefs with regards to Omani patients' adherence to antihypertensive medications.
\end{abstract}

Keywords: Hypertension; Health Behavior; Medication Adherence; Self Efficacy; Oman.

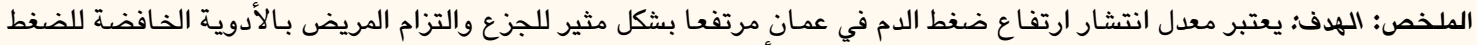

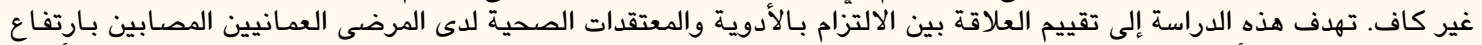

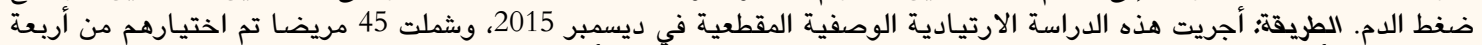

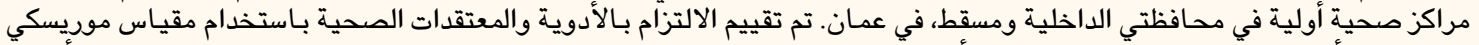

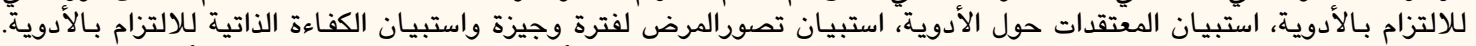

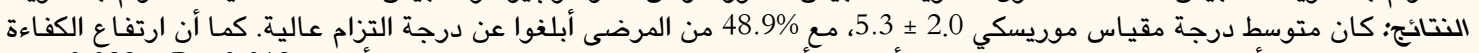

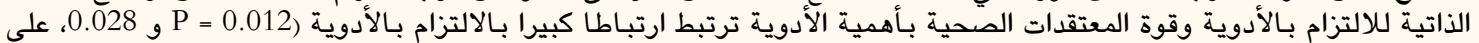

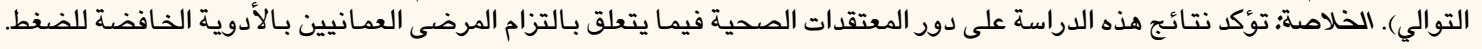

$$
\text { الكلمات المفتاحية: ارتفاع ضغط الدم؛ السلوك الصحي؛ الالتزام بالأدوية؛ الكفاءة الذاتية؛ عمان. }
$$

$\mathrm{T}$ He global prevalence of hypertension (HTN) is projected to increase markedly by 2025. ${ }^{1}$ Poor HTN management increases healthcare expenditure and complication, mortality and morbidity rates; as such, medication adherence is key. ${ }^{1}$ However, patient adherence to antihypertensive medications is inadequate globally. ${ }^{1}$ Patient beliefs about health and illness are significant predictors of medication adherence. ${ }^{2}$ Moreover, beliefs regarding the severity of a disease, self-efficacy and the benefits of medication may explain patients' attitudes towards medication adherence, as described in the Health Beliefs Model. $^{3}$
In Oman, the prevalence of HTN is high, with up to $40 \%$ of the population affected. ${ }^{4}$ Among those with HTN, 5\% have severe HTN (i.e. systolic blood pressure of $\geq 180 \mathrm{mmHg}$ or diastolic blood pressure of $\geq 110$ mmHg). ${ }^{4}$ While several studies in Oman have focused on understanding HTN-related risk factors, none to date have examined the relationship between patients' health beliefs and their adherence to antihypertensive medications. ${ }^{5,6}$ Greater knowledge of the health beliefs and medication habits of Omani patients with HTN may help clinicians and researchers develop strategies to foster medication adherence and enhance HTN management. This pilot study therefore aimed to 
describe medication adherence, self-efficacy and health beliefs among Omani patients with HTN and subsequently examine the relationship between health beliefs and medication adherence.

\section{Methods}

This descriptive cross-sectional pilot study was conducted in December 2015. Adult patients with HTN aged $\geq 21$ years old were recruited from four primary health centres in the Al Dakhiliyah and Muscat governorates in Oman. All participants had been diagnosed with HTN by their primary physician at least one year prior to the study and had been prescribed at least one antihypertensive medication. Patients were screened for eligibility according to their medical records; those with comorbidities such as diabetes, heart disease or asthma were subsequently excluded from the study. The sample size was set at 45 with $80 \%$ power in order to identify an $\mathrm{R}^{2}$ of $\geq 15.4 \%$ for the bivariate regression analyses and $\geq 23 \%$ for the multiple regression analysis based on four predictors. Consequently, the regression analyses were only powered to identify relatively large effect sizes.

All participants were asked to complete a demographic form and four questionnaires, including Arabic versions of the 8-item Morisky Medication Adherence Scale (MMAS) to measure adherence and three different health beliefs questionnaires reflecting the basic premises of the Health Beliefs Model (i.e. perceived self-efficacy, severity of the disease and the necessity of and concerns regarding the mediciation). ${ }^{3,7-12}$ For the MMAS, scores ranged from $0-8$ with a cut-off value for adequate adherence set at $\geq 6$ for the purposes of the current study. ${ }^{7}$ Beliefs about medication necessity and concerns were measured using two subscales of a validated Arabic version of the Beliefs about Medicines Questionnaire (BMQ) obtained from the main developer of the original 11-item questionnaire, similarly scored on a fivepoint Likert scale. ${ }^{10,12}$ Beliefs about HTN severity were measured using the 8-item Brief Illness Perception Questionnaire (BIPQ), in which each item was rated on a scale of $0-10$, with the overall score ranging from $0-80 .{ }^{9}$ Self-efficacy for medication adherence was measured using the 13-item revised Medication Adherence Self-Efficacy Scale (MASES-R), with each item rated using a four-point Likert scale. ${ }^{8}$ For all questionnaires, higher scores reflect greater adherence, stronger beliefs and greater self-efficacy, respectively; in addition, previous research has confirmed the validity and reliability of these tools. ${ }^{7-11}$ Permission to use these questionnaires was obtained from the relevant developers, including permission to use the Arabic versions of the tools. Only the BIPQ and MASES-R questionnaires were translated to Arabic by the researchers themselves; this was done using previously described translation methods. ${ }^{13}$

Descriptive statistics including means, standard deviations, frequencies and percentages were computed using the Statistical Package for the Social Sciences (SPSS), Version 23.0 (IBM Corp., Armonk, New York, USA). Relationships between demographic characteristics, health beliefs and medication adherence were assessed using a bivariate Pearson's correlation analysis for continuous variables and a oneway analysis of variance test for categorical variables. Multiple linear regression analysis was conducted to examine the independent influence of beliefs on medication adherence. Variables were input into the regression analysis model using the enter method. A $P$ value of $\leq 0.050$ was considered statistically significant.

Ethical approval for this pilot study was obtained from both the University of North Carolina at Chapel Hill, Chapel Hill, North Carolina, USA (IRB \#15-0684), and the Research and Ethical Review and Approval Committee of the Ministry of Health in Muscat. All of the participants provided informed written consent prior to their inclusion in the pilot study.

\section{Results}

A total of 45 patietns were included in this pilot study. Table 1 illustrates the demographic characteristics of the participants. The mean MMAS score was $5.3 \pm 2.0$ and $48.9 \%$ of the subjects were classified as high adherers. In total, $95.6 \%$ reported that they had not missed a medication dose over the previous two weeks, $66.7 \%$ claimed that they were never annoyed about complying with their medication requirements, $64.4 \%$ reported never cutting back or stopping their medications without informing their doctor and $64.4 \%$ stated that they continued to take their medications when travelling. Moreover, $50.0 \%$ of the subjects reported they had no difficulty remembering to take their medications.

The mean score for the necessity subscale of the BMQ was $3.8 \pm 0.8$. Most subjects agreed to the following: that their current (88.9\%) and future (55.5\%) health depended on the medication; that medications protected their health from becoming worse (84.4\%); and that, without the medication, they would become very ill (57.8\%). However, $33.3 \%$ of the subjects were uncertain as to whether their future health depended on the medications and whether their lives would be impossible without the medicine. The mean score for the concerns subscale of the BMQ was $2.7 \pm 0.7$. 
Table 1: Demographic characteristics and medication adherence and health belief scores* of Omani patients with hypertension at four primary health centres in Oman $(\mathrm{N}=45)$

\begin{tabular}{|c|c|}
\hline Variable & n (\%) \\
\hline Mean age in years (range) & $52.1 \pm 14.6(23-84)$ \\
\hline \multicolumn{2}{|l|}{ Gender } \\
\hline Men & $16(35.6)$ \\
\hline Women & $29(64.4)$ \\
\hline $\begin{array}{l}\text { Mean number of years with HTN } \\
\text { (range) }\end{array}$ & $7.3 \pm 6.9(1-30)$ \\
\hline $\begin{array}{l}\text { Mean number of antihypertensive } \\
\text { medications prescribed (range) }\end{array}$ & $1.9 \pm 1.1(1-5)$ \\
\hline $\begin{array}{l}\text { Mean frequency of daily dose } \\
\text { (range) }\end{array}$ & $1.6 \pm 0.80(1-4)$ \\
\hline \multicolumn{2}{|l|}{ Residence } \\
\hline Al Dakhiliyah & $32(71.1)$ \\
\hline Muscat & $13(28.9)$ \\
\hline \multicolumn{2}{|l|}{ Marital status } \\
\hline Single & $4(8.9)$ \\
\hline Married & $28(62.2)$ \\
\hline Widowed & $13(28.9)$ \\
\hline \multicolumn{2}{|l|}{ Monthly income in $\mathrm{OMR}^{+}$} \\
\hline None & $15(33.3)$ \\
\hline$<150$ & $8(17.8)$ \\
\hline $150-499$ & $9(20.0)$ \\
\hline $500-999$ & $2(4.4)$ \\
\hline$>1,000$ & $9(20.0)$ \\
\hline \multicolumn{2}{|l|}{ Education level } \\
\hline Illiterate & $19(42.2)$ \\
\hline Ability to read and write only & $4(8.9)$ \\
\hline Primary or preparatory & $4(8.9)$ \\
\hline High school & $12(26.7)$ \\
\hline University or higher & $6(13.3)$ \\
\hline \multicolumn{2}{|l|}{ Employment status $^{\ddagger}$} \\
\hline Government sector & $7(15.6)$ \\
\hline Private sector & $4(8.9)$ \\
\hline Self-employed & $4(8.9)$ \\
\hline Unemployed & $26(57.8)$ \\
\hline Retired & $3(6.7)$ \\
\hline \multicolumn{2}{|l|}{ Smoking status } \\
\hline Nonsmoker & $43(95.6)$ \\
\hline Smoker & $2(4.4)$ \\
\hline
\end{tabular}

$\begin{array}{lr}\text { Alcohol consumption } & \\ \text { No } & 44(97.8) \\ \text { Yes } & 1(2.2)\end{array}$

Mean adherence and health belief scores (range)

MMAS

$5.3 \pm 2.0(0.75-8.0)$

BMQ-C

$2.7 \pm 0.7(1.2-4.7)$

BMQ-N

$3.8 \pm 0.8(2.0-5.0)$

BIPQ

$27.0 \pm 12.2(1.0-56.0)$

MASES-R

$3.2 \pm 0.7(1.6-4.0)$

HTN = hypertension $;$ OMR = Omani rials; $M M A S=$ Morisky Medication Adherence Scale; BMQ-C = Beliefs about Medicine Questionnaire concerns subscale; $B M Q-N=$ Beliefs about Medicine Questionnaire necessity subscale; $B I P Q=$ Brief Illness Perception Questionnaire; MASES-R = revised Medication Adherence SelfEfficacy Scale.

"Medication adherence was assessed using an Arabic version of the 8-item Morisky Medication Adherence Scale while health beliefs were assessed using Arabic versions of the 11-item Beliefs about Medicine Questionnaire, 8-item Brief Illness Perception Questionnaire and 13-item revised Medication Adherence Self-Efficacy Scale. ${ }^{7-10,12}$

${ }^{+}$Total dataset for this variable was 43 as information for two subjects was unavailable.

${ }^{\ddagger}$ Total dataset for this variable was 44 as information for one subject was unavailable.

More than half of the subjects disagreed or strongly disagreed with the following statements: that the antihypertensive medicine disrupted their life (68.2\%); that having to take the medication worried them $(57.8 \%)$; and that the medicine had unpleasant side-effects (51.1\%). However, some of the subjects reported concerns about becoming too dependent on the medication (44.4\%) and that the medication was a mystery to them (35.5\%).

The mean BIPQ score was $27.0 \pm 12.2$. A total of $70.0 \%$ of the subjects reported that HTN had minimal or no effect on their lives; $100.0 \%$ believed that they had control over their HTN; 66.7\% believed that they had few or no symptoms of HTN; and 72.7\% reported having minimal or no concern regarding their HTN diagnosis. The mean MASES-R score was $3.2 \pm 0.7$. Most subjects were confident in their ability to take their medication between meals (70.5\%) or more than once a day (59.1\%). In addition, the majority reported that they would continue to take the medication even when they were worried about having to take it for the rest of their lives (54.5\%) or when they did not have any symptoms (54.5\%) or felt well (52.3\%). The Cronbach's alpha values of the MMAS, the necessity and concerns subscales of the BMQ, BIPQ and MASES-R tools were $0.72,0.78,0.70,0.68$ and 0.90 , respectively.

No significant correlations were observed between medication adherence and the demographic characteristics of the sample. However, there was a significant negative correlation between health beliefs 
Table 2: Linear regression analysis* of health belief variables predicting medication adherence ${ }^{\dagger}$ among Omani patients with hypertension at four primary health centres in Oman $(N=45)$

\begin{tabular}{|c|c|c|c|c|c|}
\hline Variable & $\begin{array}{c}\text { Unstandardised } \beta \\
\text { coefficient } \pm S E\end{array}$ & $\begin{array}{l}\text { Standardised } \beta \\
\text { coefficient }\end{array}$ & $\mathbf{t}$ & $P$ value & $95 \%$ CI \\
\hline BIPQ & $-0.034 \pm-0.024$ & -0.211 & -1.389 & 0.173 & $-0.83-0.15$ \\
\hline MASES-R & $1.067 \pm 0.405$ & 0.363 & 2.363 & 0.012 & $0.25-1.89$ \\
\hline BMQ-C & $-0.303 \pm-0.402$ & -0.112 & -0.755 & 0.455 & $-1.12-0.51$ \\
\hline
\end{tabular}

$S E=$ standard error $; C I=$ confidence interval; $B I P Q=$ Brief Illness Perception Questionnaire; $M A S E S-R=$ revised Medication Adherence SelfEfficacy Scale; BMQ-C = Beliefs about Medicine Questionnaire concerns subscale; BMQ-N = Beliefs about Medicine Questionnaire necessity subscale.

$* R^{2}=0.33{ }^{\dagger}{ }^{\dagger}$ Health beliefs were assessed using Arabic versions of the 11-item Beliefs about Medicine Questionnaire, 8-item Brief Illness Perception Questionnaire and 13-item revised Medication Adherence Self-Efficacy Scale while medication adherence was assessed using an Arabic version of the 8-item Morisky Medication Adherence Scale. ${ }^{7-10,12}$

regarding perceived HTN severity and medication adherence $(\mathrm{r}=-0.32 ; P=0.030)$ and a significant positive correlation between perceived self-efficacy and medication adherence $(r=0.44 ; P=0.003)$. No significant correlation was found between medication adherence and beliefs about medication necessity $(\mathrm{r}=0.25 ; P=0.100)$ or medication concerns $(\mathrm{r}=-0.28$; $P=0.060)$. The regression model was significant $\left(F_{(4,39)}=4.89 ; P=0.003\right)$ and explained $33.0 \%$ of the variation in medication adherence. Self-efficacy $(B=1.067 ; P=0.012)$ and beliefs about medication necessity $(B=0.777 ; P=0.028)$ were positively associated with medication adherence [Table 2]. Self-efficacy and necessity together explained 26.0\% of the variation in medication adherence.

\section{Discussion}

In the current study, the overall adherence rate was less than $50 \%$, which is consistent with reports from the World Health Organization and indicative of the need for collaborative efforts to improve medication adherence in Oman. ${ }^{1}$ High self-efficacy was significantly associated with medication adherence among Omani patients with HTN, a finding which is consistent with that reported in the literature, regardless of differences in measures, study designs or culture. ${ }^{8,14}$ Self-efficacy is a critical factor in creating and sustaining health behaviours because it empowers individuals, giving them confidence in maintaining positive health behaviours (e.g. medication adherence). ${ }^{15}$ Such findings highlight the fact that self-efficacy needs to be a central component in ensuring medication adherence across cultures and populations. The current study also found that stronger beliefs about the necessity of antihypertensive medications were related to higher medication adherence; other studies, including those involving Arab populations, have reported similar results. ${ }^{2,14}$
No relationship was found between concerns about antihypertensive medications and medication adherence in the present study; this is inconsistent with the findings of previous research., ${ }^{2,14}$ In the current study, subjects seemed more anxious about becoming overly dependent on their medications. It is likely that the low adherence level noted among patients with more concerns about their medications could be improved by addressing these fears when developing a plan of care, particularly with major concerns related to the longterm consequences or side-effects of the medication or fears of dependency. When planning programmes that target health behaviour, the contextual meaning of health to an individual, including their health beliefs, is significant. ${ }^{3}$ Furthermore, it is crucial to incorporate health beliefs and self-efficacy as key components of health education or counselling programmes designed for members of the general public in Oman.

This pilot study was subject to certain limitations. As a cross-sectional correlational study design was used, causal relationships and long-term adherence rates could not be inferred. Additionally, the small sample size, use of convenience sampling to recruit the subjects and sole inclusion of patients with HTN limited the generalisability of the findings to the larger Omani population and increased the likelihood of selection bias. Furthermore, the use of a self-reported measure to examine medication adherence could have caused recall bias and an overestimation of actual adherence rates. Therefore, additional studies with objective measures of medication adherence are needed. Future studies using a longitudinal design with a larger and randomised sample from different regions of Oman are recommended to improve the generalisability of these findings and examine medication adherence over time. 


\section{Conclusion}

This pilot study was conducted to examine the relationship between Omani patients' health beliefs and their antihypertensive medication adherence. Overall, health beliefs regarding the necessity of the medication and perceived self-efficacy were significantly associated with medication adherence. These findings could be used to develop health education programmes on HTN management based on health beliefs to help improve overall adherence to HTN medications in Oman.

\section{CONFLICT OF INTEREST}

The authors declare no conflicts of interest.

\section{FUNDING}

No funding was received for this pilot study.

\section{References}

1. World Health Organization. A global brief on hypertension Silent killer, global public health crisis. From: www.who. int/cardiovascular_diseases/publications/global_brief_ hypertension/en/ Accessed: Jun 2017

2. Rajpura JR, Nayak R. Role of illness perceptions and medication beliefs on medication compliance of elderly hypertensive cohorts. J Pharm Pract 2014; 27:19-24. doi: $10.1177 / 0897190013493806$.

3. Rosenstock IM, Strecher VJ, Becker MH. Social learning theory and the Health Belief Model. Heal Educ Q 1988; 15:175-83.

4. Al Riyami A, Elaty MA, Morsi M, Al Kharusi H, Al Shukaily W, Jaju S. Oman World Health Survey: Part 1 - Methodology, sociodemographic profile and epidemiology of non-communicable diseases in Oman. Oman Med J 2012; 27:425-43.

5. Abd El-Aty MA, Meky FA, Morsi MM, Al-Lawati JA, El Sayed MK. Hypertension in the adult Omani population: Predictors for unawareness and uncontrolled hypertension. J Egypt Public Health Assoc 2015; 90:125-32. doi: 10.1097/01. EPX.0000470547.32952.cf.
6. Al-Maqbali AA, Temple-Smith M, Ferler J, Blackberry I. Prevalence and determinants of pre-hypertension among Omani adults attending non-communicable disease screening program in primary care setting in Sohar city. Oman Med J 2013; 28:316-23. doi: 10.5001/omj.2013.94

7. Morisky DE, Ang A, Krousel-Wood M, Ward HJ. Predictive validity of a medication adherence measure in an outpatient setting. J Clin Hypertens (Greenwich) 2008; 10:348-54. doi: 10.1111/j.1751-7176.2008.07572.x.

8. Fernandez S, Chaplin W, Schoenthaler AM, Ogedegbe G. Revision and validation of the Medication Adherence SelfEfficacy Scale (MASES) in hypertensive African Americans. J Behav Med 2008; 31:453-62. doi: 10.1007/s10865-008-9170-7.

9. Broadbent E, Petrie KJ, Main J, Weinman J. The Brief Illness Perception Questionnaire. J Psychosom Res 2006; 60:631-7. doi: 10.1016/j.jpsychores.2005.10.020.

10. Horne R, Weinman J, Hankins M. The Beliefs about Medicines Questionnaire: The development and evaluation of a new method for assessing the cognitive representation of medication. Psychol Health 1999; 14:1-24. doi: 10.1080/ 08870449908407311

11. Zyoud SH, Al-Jabi SW, Sweileh WM, Morisky DE. Relationship of treatment satisfaction to medication adherence: Findings from a cross-sectional survey among hypertensive patients in Palestine. Health Qual Life Outcomes 2013; 11:191. doi: 10.1186/1477-7525-11-191.

12. Jamous RM, Sweileh WM, El-Deen Abu Taha AS, Zyoud SH. Beliefs about medicines and self-reported adherence among patients with chronic illness: A study in Palestine. J Family Med Prim Care 2014; 3:224-9. doi: 10.4103/2249-4863.141615.

13. World Health Organization. Management of substance abuse: Process of translation and adaptation of instruments. From: www.who.int/substance_abuse/research_tools/translation/en/ Accessed: Jun 2017.

14. Kamran A, Sadeghieh Ahari S, Biria M, Malepour A, Heydari H. Determinants of patient's adherence to hypertension medications: Application of Health Belief Model among rural patients. Ann Med Health Sci Res 2015; 4:922-7. doi: 10.4103/2141-9248.144914.

15. Lorig K, Laurent DD, Plant K, Krishnan E, Ritter PL. The components of action planning and their associations with behavior and health outcomes. Chronic Illn 2014; 10:50-9. doi: $10.1177 / 1742395313495572$. 